\title{
Role of Laparoscopy in Diagnosis and Treatment of Acute Abdominal Pain
}

Mohammed Fathi Sharaf, Eslam Taha Ghalwash, Abd Al Rahman Mohammed Ali

Department of General and Laparoscopic Surgery, El-Hussein University Hospitals,

Faculty of Medicine, Al-Azhar University, Cairo, Egypt

Corresponding author: Name: Abd Al Rahman Mohammed Ali, E-Mail: drabdom2020@gmail.com, TEL: 00201000317976

\begin{abstract}
Background: Abdominal pain is a common presentation at the surgical department. Emergency laparoscopy in patients with "acute abdomen" is a part of common surgical practice.

Aim: Evaluation of the role of laparoscopy in management of acute abdominal pain

Methods: 100 patients with acute abdominal pain presented to the Department of Surgery, Al-Azhar University, El-Hussein and El Minia Health Insurance Hospitals were included in the study during the period from April 2018 to April 2019. They were divided into two groups: known preoperative diagnosis (therapeutic $n=67$ patients) and unknown (diagnostic and therapeutic $n=33$ patients). Their ages ranged between 12 and 60 years old ( 35 patients were males and 65 patients were females). Laparoscopy was performed for all patients under general anesthesia.

Results: The definitive diagnosis was established in $99 \%$ of cases. $64 \%$ of those cases were managed successfully by use of laparoscopy and conversion rate was $33 \%$. Time required for each operation varied according to the procedure, intraoperative morbidity was $7 \%$, post-operative complications were $11 \%$. The mortality of study was $1 \%$. Conclusions: laparoscopic intervention for abdominal emergencies is as safe, feasible and effective. It results in minor trauma, has a rapid postoperative recovery, and reduces morbidity. Laparoscopy can help to avoid unnecessary non- therapeutic laparotomies. It can also help to guide the operating surgeon for choosing the proper targeted incision.
\end{abstract}

Keywords: Acute abdomen, Emergency, Laparoscopy

\section{INTRODUCTION}

The term "Acute abdomen" is generally used to describe any acute abdominal pain, with duration of less than one week that may require urgent or immediate intervention, including emergency surgery. Although acute abdominal pain is often caused by an intra-abdominal pathology, it may also be a manifestation of an extra- abdominal disease (e.g. thoracic or systemic pathology) ${ }^{(1)}$.

Acute abdominal pain can present a diagnostic dilemma. Clinical examination often fails to yield a diagnosis in patients with acute abdomen, particularly when the symptoms and signs are compounded by obesity. Blood investigations may be diagnostic in some cases, but in most other scenarios they simply indicate the presence of an inflammatory process. Radiological investigations may suggest a diagnosis, but may often provide false-negative results ${ }^{(2)}$.

Laparoscopy as a minimally tool can accurately and quickly confirm the diagnosis and reduce both delay in diagnosis and non-therapeutic laparotomy rate. Above all with the improvement in the technology and skills there is an expanding potential for carrying out therapeutic procedures at the same setting. Laparoscopy can be considered in acute abdominal pain for following reasons; diagnosis, diagnosis and treatment, and to determine the best incision just before laparotomy ${ }^{(3)}$.

The rapidly increasing popularity of laparoscopy may be attributed to several factors including its applicability, high diagnostic yield, therapeutic management in the same sitting (in cases where on table diagnosis is possible), ability to manage most coexisting conditions, low patients morbidity and reduced hospital stay and expenditure ${ }^{(4)}$.

\section{Epidemiology:}

Acute abdominal pain is a common presentation. It accounts for 5-25\% of all emergency department visits annually. Each year, about 450 females and 180 males per 100,000 are hospitalized for acute abdominal pain. It may affect the very young, the very old, either sex, and all socioeconomic ${ }^{(5)}$. However some causes are frequent in the pediatric population (like appendicitis) or are strictly related to the gender (i.e. gynaecological causes). It is also important to consider special populations such as the elderly or oncologic patients (6).

\section{PATIENTS AND METHODS}

The study was carried out at the Emergency Department, El-Hussein University Hospital and El Minia Health Insurance Hospital over one year period. 100 patients who underwent diagnostic and/or therapeutic laparoscopy for "Acute abdomen" between April 2018 and April 2019.

\section{Inclusion criteria:}

All patients with acute abdominal pain less than 7 days. Age between 12-60 years old, hemodynamically stable and controlled coagulopathy.

\section{Exclusion Criteria:}

Cases below 12 or above 60 years old, haemodynamic instability till stabilization of the case, uncontrolled coagulopathy, multiple previous laparotomies and elective abdominal or pelvic surgical procedures. Patients with intestinal obstruction with diffuse abdominal distension. Those who did not give consent. Accidents and trauma patients. Patient with any contraindication to pneumoperitoneum. The 
elderly in which a surgical or anaesthetic intervention outweighed the theoretic benefits of laparoscopy

\section{Preoperative evaluation and preparation:}

All patients who presented to the Emergency Department with acute abdominal pain during the study period and underwent preoperative evaluation in the form of history taking, physical examination and investigations (coagulation profile, complete blood count, random blood sugar, serum amylase, liver and kidney functions tests, plain X-ray chest (erect), plain $\mathrm{X}$-ray abdomen (erect and supine) and pelviabdominal US, CT scan of the abdomen and pelvis were done.

\section{Operative Technique:}

After placement of the first port, a detailed examination of the peritoneal cavity is performed. Depending on the site of suspected pathology, all relevant structures are grossly examined for signs of inflammation (e.g. pus, inflammatory adhesions, phlegmon). If an obvious pathology is identified, a therapeutic procedure (laparoscopic or open) can be undertaken in the same setting. After initial inspection, $5-\mathrm{mm}$ and / or 10-mm additional ports are placed as necessary, depending upon the planned procedure. In general, ports should be placed under direct vision and should be positioned to form an equilateral triangle or a diamond, taking into account the camera position and the distance from the operative target. Before the procedure is terminated, a meticulous abdominal examination is carried out to ensure adequate hemostasis. Ports are removed under direct vision to ensure that there is no bleeding or visceral herniation. All port sites larger than $5 \mathrm{~mm}$ should be closed with absorbable sutures. The skin is then closed with subcuticular sutures.

\section{Ethical approval and written informed consent:} An approval of the study was obtained from Al Azhar University Ethical Committee. Every patient signed an informed written consent for acceptance of the operation.

\section{RESULTS}

In this study 100 patients were included. Their ages ranged between 12 - 60 years old ( mean $=39.5$ years). 35 patients were males and 65 patients were females who underwent diagnostic and/or therapeutic laparoscopy for "Acute abdomen" between April 2018 and April 2019 (Table 1).

Table (1): Comparison between group A and group B as regards gender

\begin{tabular}{|c|c|r|r|r|r|r|r|}
\hline \multicolumn{2}{|c|}{} & \multicolumn{2}{c|}{ Group A (n= 67) } & \multicolumn{2}{c|}{ Group B (n= 33) } & \multicolumn{2}{c|}{ Chi square test } \\
\cline { 2 - 8 } \multicolumn{2}{|c|}{} & \multicolumn{2}{c|}{ No } & \% & No & \% & \multicolumn{2}{|c|}{$\mathbf{X}^{\mathbf{2}}$} & P value \\
\hline \multirow{2}{*}{ Gender } & Male & 20 & $29.9 \%$ & 15 & $45.5 \%$ & \multirow{2}{*}{2.366} & 0.124 \\
\cline { 2 - 7 } & Female & 47 & $70.1 \%$ & 18 & $54.5 \%$ & \\
\hline
\end{tabular}

Patients were divided into 2 groups; A and B. Group A included 67 patients "with a definite clinical diagnosis" who underwent therapeutic laparoscopy, whereas group B included 33 patients "without a definite clinical diagnosis" who underwent diagnostic laparoscopy.

In our study diagnostic laparoscopy confirmed the preoperative clinical diagnosis in 67 patients $(100 \%)$ and was beneficial diagnostic tool in 32 patients $(97 \%)$. Of them, 64 patients $(64 \%)$ underwent successful therapeutic procedures with laparoscopy. Conversion to open surgery was done for 32 patients (32\%) through targeted incision. Intraoperative morbidity occurred in 7 patients $(7 \%)$ while postoperative morbidity occurred in 11 patients $(11 \%)$ (Table 2).

Table (2): Comparison between group A and group B as regards morbidity and early postoperative complication

\begin{tabular}{|c|c|c|c|c|c|c|c|}
\hline & \multicolumn{2}{|c|}{ Group A $(n=67)$} & \multicolumn{2}{|c|}{ Group B $(n=33)$} & \multicolumn{2}{|c|}{ Chi square test } \\
\hline & & No & $\%$ & No & $\%$ & $\mathrm{X}^{2}$ & $P$ value \\
\hline \multirow{4}{*}{$\begin{array}{c}\text { Morbidity } \\
\text { Intra- } \\
\text { operative } \\
\text { complications }\end{array}$} & Bowel injury & 3 & $4.5 \%$ & 1 & $3.0 \%$ & \multirow{4}{*}{4.000} & \multirow{4}{*}{0.406} \\
\hline & Liver injury & 1 & $1.5 \%$ & 0 & $0.0 \%$ & & \\
\hline & Anesthesia-related & 1 & $1.5 \%$ & 0 & $0.0 \%$ & & \\
\hline & CBD injuryltransection & 1 & $1.5 \%$ & 0 & $0.0 \%$ & & \\
\hline \multirow{4}{*}{$\begin{array}{l}\text { Early Post- } \\
\text { operative } \\
\text { complications }\end{array}$} & Fever & 1 & $1.5 \%$ & 2 & $6.1 \%$ & \multirow{4}{*}{0.557} & \multirow{4}{*}{0.906} \\
\hline & Wound infection & 1 & $1.5 \%$ & 3 & $9.1 \%$ & & \\
\hline & Ileus & 1 & $1.5 \%$ & 1 & $3.0 \%$ & & \\
\hline & $\begin{array}{l}\text { Leakage of duodenal } \\
\text { contents }\end{array}$ & 1 & $1.5 \%$ & 1 & $3.0 \%$ & & \\
\hline
\end{tabular}

No missed pathology in our study. Only one patient died in our study (mortality $=1 \%$ ). In this study, the mean postoperative hospital stay after laparoscopy was 2.1 days and 4.55 days after open surgery (Table 3 ). Wound infections occurred in $4 \%$ of patients. 
Table (3): Comparison between group A and group B as regards Postoperative hospital stay (days)

\begin{tabular}{|c|c|c|c|c|c|}
\hline \multicolumn{2}{|l|}{} & \multirow{2}{*}{$\begin{array}{c}\text { Group A } \\
(\mathbf{n = 6 7})\end{array}$} & \multirow{2}{*}{$\begin{array}{c}\text { Group } \\
(\mathbf{B}=33)\end{array}$} & \multicolumn{2}{|c|}{$\begin{array}{c}\text { Independent } \\
\text { t test }\end{array}$} \\
\cline { 5 - 7 } & & $\mathbf{T}$ & P value \\
\hline $\begin{array}{c}\text { Postoperative } \\
\text { hospital stay } \\
\text { (days) }\end{array}$ & $\begin{array}{c}\text { Mean } \\
\pm \text { SD }\end{array}$ & $1.9 \pm 2.0$ & $2.9 \pm 1.2$ & 2.643 & 0.009 \\
\hline
\end{tabular}

Group A included 67 patients "with a definite clinical diagnosis" who underwent therapeutic laparoscopy [laparoscopic appendectomy (45), laparoscopic cholecystectomy (22)]. These therapeutic procedures were successfully completed laparoscopically in 50 cases, laparoscopic drainage of pericholecystic abscess in one case, while 16 cases required conversion to open surgery.

On the other hand, group B included 33 patients "without a definite clinical diagnosis" who underwent diagnostic laparoscopy. This group was further subdivided into 2 subgroups (B.1 and B.2). Subgroup B.1 included. 17 patients who underwent either a diagnostic laparoscopic procedure only $(n=4)$ or a combined diagnostic-therapeutic laparoscopic procedure $(n=13)$ and did not require conversion to open surgery. Subgroup B. 2 included 16 patients who required conversion from a laparoscopic to an open surgical procedure (Table 4) through different abdominal incisions (Table 5).

Table (1): Comparison between group A and group $\mathrm{B}$ as regards conversion rates and mortality rate

\begin{tabular}{|c|l|l|l|l|l|l|}
\hline & \multicolumn{2}{|l|}{$\begin{array}{l}\text { Group A } \\
(\mathbf{n = 6 7 )}\end{array}$} & \multicolumn{2}{|l|}{$\begin{array}{l}\text { Group } \\
(\mathbf{n = 3 3})\end{array}$} & \multicolumn{2}{|l|}{$\begin{array}{l}\text { Chi } \\
\text { test }\end{array}$} \\
\cline { 2 - 7 } & No & $\%$ & No & $\%$ & $\mathbf{X}^{2}$ & $\begin{array}{l}\text { P } \\
\text { value }\end{array}$ \\
\hline $\begin{array}{l}\text { Conversion } \\
\text { rates }\end{array}$ & 16 & $23.9 \%$ & 16 & $48.5 \%$ & 6.151 & 0.013 \\
\hline $\begin{array}{l}\text { 30-day } \\
\text { mortality } \\
\text { rate }\end{array}$ & 1 & $1.5 \%$ & 0 & $0 \%$ & 0.498 & 0.480 \\
\hline
\end{tabular}

Table (5): Different types of abdominal incisions used for conversion to open surgery in group B patients [subgroup $\mathrm{B} 2(\mathrm{n}=16)]$

\begin{tabular}{|l|l|l|}
\hline Type of abdominal incisions & No & \% \\
\hline Midline laparotomy & 3 & $18.8 \%$ \\
\hline $\begin{array}{l}\text { Upper midline laparotomy } \\
\text { (Above umbilicus) }\end{array}$ & 1 & $6.3 \%$ \\
\hline $\begin{array}{l}\text { Lower midline laparotomy } \\
\text { (Below umbilicus) }\end{array}$ & 5 & $31.3 \%$ \\
\hline Grid iron incision & 5 & $31.3 \%$ \\
\hline $\begin{array}{l}\text { Low transverse } \\
\text { (phannenstiel) incision }\end{array}$ & 2 & $12.5 \%$ \\
\hline
\end{tabular}
Therefore, overall in our study, laparoscopy wasduodenal fistula where open exploration was done and diagnostic only in 20 cases [ 4 cases in subgroup B.1 and primary repair of the duodenal fistula was performed. 16 cases in subgroup B. 2], therapeutic only in 51 cases [alFistula had recurred. The general condition of the patient cases in group A], and as both diagnostic and therapeutic ${ }^{\mathrm{w} o r s e n e d}$ and patient transferred to the intensive care unit. On $12^{\text {th }}$ postoperative day, patient died from severe sepsis

in 13 cases [cases in subgroup B.1].

Unnecessary non-therapeutic laparotomies were avoided in 4 cases in group B. In those 4 cases (in subgroup B.1), only a diagnostic laparoscopic procedure was undertaken without needing to perform any therapeutic procedure [acute pancreatitis $(n=2)$, negative laparoscopy $(n=2)$. Hence, those patients were spared the morbidity of unnecessary non-therapeutic midline laparotomies.

\section{DISCUSSION}

An acute abdomen is a common surgical emergency. It is apotentially lethal condition and the exact diagnosis of this presentation is usually difficult. It is the duty of the attending surgeon to finalize the diagnosis and management properly. To achieve this goal, exploratory laparotomy may be utilized. The advent of laparoscopic techniques has improved the approach to this problem and could save the patient an unnecessary negative laparotomy.

The diagnostic accuracy in our study (99\%) and therapeutic efficacy of laparoscopy in our study (64\%) are consistent with those reported in previous studies. According to the international literature, the diagnostic accuracy of laparoscopy in patients with acute abdomen ranges from 85 to $100 \%$. In one study, laparoscopy could establish a definite diagnosis in 93 to $100 \%$ of cases, and could accomplish a definitive treatment of the underlying disease in 44 to $73 \%$ of cases (7). In another study, a definitive diagnosis was accomplished in $85.7 \%$ of cases, laparoscopy (8). In a third study, laparoscopy was diagnostic in $100 \%$ of cases and could accomplish treatment in $94 \%$ of those case ${ }^{(9)}$. This indicates that the therapeutic efficacy was relatively higher in patients who underwent laparoscopy after a definite clinical diagnosis had been made preoperatively.

In our study, the intra-operative complications were $6 \%$ in group A and $1 \%$ in group B patients. However, the rate of post-operative complications was relatively higher in group B (7\%) compared to group A patients (4\%).

The overall morbidity rate in our study is almost consistent with previous studies which reported various complications in patients undergoing laparoscopy for acute abdomen, with morbidity rates ranging from 0 to $24 \%{ }^{(8)}$.

Obviously, the overall rate of conversion in our study (32\%) was higher than the rates reported in previous studies. For example, in a retrospective review of 514 patients who underwent laparoscopy for acute abdominal pain, the conversion rate was $2.2 \%{ }^{(10)}$. In another series of 25 patients, the conversion rate was $19 \%$ and the reasons behind conversion were either a difficult procedure or a failure to establish a definite diagnosis ${ }^{(11)}$.

The only patient who died in this study was a 62 -years old female diabetic patient in group A in whom diagnostic laparoscopy revealed pericholecystic abscess. Drainage only was done, two days postoperative patient developed primary repair of the duodenal fistula was performed.
Fistula had recurred. The general condition of the patient and $90.6 \%$ of those cases were successfully treated by 
and organ dysfunction. The mortality rate in our study coincides with the rates reported in the literature. In a study by Chung et al. ?????, there was no procedure-related ${ }^{4}$ mortality, and the three deaths that were reported were due to extensive bowel infarctions. Other studies reported mortality rates ranging from 0 to $5 \%{ }^{(12)}$. In a recent case series of 50 patients who underwent laparoscopy for acute abdomen, the mortality rate was $0 \%{ }^{(9)}$.

\section{CONCLUSION}

Laparoscopic intervention for acute abdominal pain is safe, feasible and effective. It results in minor trauma, avoidance of extensive preoperative investigations or delays in operative intervention, rapid postoperative recovery and less morbidity. These features make laparoscopy to be an excellent alternative to open surgery in the management of abdominal emergencies. Also, laparoscopy can help to avoid unnecessary non-
therapeutic laparotomies. It can also help to guide the surgeons for choosing the proper targeted incision in patients where a definitive treatment cannot be completed laparoscopically.

\section{Conflicts of interest:}

There are no conflicts of interest.

\section{Authorship:}

All authors have a substantial contribution to the article.

\section{REFERENCES}

1. Mayumi T, Yoshida M, Tazuma S et al. (2016): The Practice Guidelines for Primary Care of Acute Abdomen. Japanese Journal of Radiology, 34 (1) : 80-115.

2. Golash V, Willson PD (2005): Early laparoscopy as a routine procedure in the management of acute abdominal pain: a review of 1,320 patients. Surgical endoscopy and other interventional techniques, 19 (7): 882-5.

3. Hussain A (2014): Role of laparoscopy in emergency abdominal surgery. https://www.semanticscholar.org/paper/\%5BThe-role-of-
laparoscopy-in-emergency-abdominal-Bal\%C3\%A9nHerrera/8db95fda081517b13be10421c05d00f908864f5f

4. Rubbia A, Faryal GA and Javeria I et al. (2015): Role of diagnostic laparoscopy in patients with acute or chronic nonspecific abdominal pain. World Journal of laparoscopic surgery, 8 (1): 7-12.

5. Grundmann RT, Petersen M, Lippert H et al. (2010): The acute (surgical) abdomen-epidemiology, diagnosis and general principles of management." Zeitschrift fur Gastroenterologie, 48 (6): 696-706.

6. Muhammad TA, Shahzad HU, Muhammad AB (2016): laparoscopy in unexplained abdominal pain. Department of general surgery, Pakistan of medical sciences, Islamabadpakistan. Journal ayub medical coll Abbottabad, 28 (3): 461 -4 .

Beauchamp RD, Evers BM, Mattox KL (2004): The Acute Abdomen. In: Sabiston Textbook of Surgery, the Biological Basis of Modern Surgical Practice. www.elsevier.com > Books \& Journals > Sabiston Textbook of Surgery

8. Agresta F, Mazzarolo G, Ciardo LF et al. (2008): The laparoscopic approach in abdominal emergencies: has the attitude changed? A single-center review of a 15-year experience. Surgical Endoscopy, 22 (5): 1255-62.

9. Babannavar PB, Thejeswi P, Ravishankar et al. (2013): Role of Laparoscopy in Diagnosis and Management of Acute Abdomen - In South Indian Population. https://print.ispub.com/api/0/ispub-article/14610

10. Karamanakos SN, Sdralis E, Panagiotopoulos S et al. (2010): Laparoscopy in the emergency setting: a retrospective review of 540 patients with acute abdominal pain. Surgical Laparoscopy Endoscopy \& Percutaneous Techniques, 20 (2): 119-24.

11. Mehta S, Juneja I, Udani D (2008): Role of diagnostic laparoscopy in management of acute abdomen. print.ispub.com > api > ispub-article

12. Hori Y (2008): Diagnostic laparoscopy guidelines: This guideline was prepared by the SAGES Guidelines Committee and reviewed and approved by the Board of Governors of the Society of American Gastrointestinal and Endoscopic Surgeons (SAGES).Surgical Endoscopy, 22 (5): 1353-83. 